\title{
Adaptation of The 3 Mistakes of My Life into the Film Kai Po Che
}

\section{Dr. Nagmani Alok}

Senior Faculty (English), H.M.S., Darbhanga, Bihar, India

\begin{abstract}
Chetan Bhagat is one of the most popular and renowned living authors of India. He is one of the favorite novelists of young India and has many time been crowned as an icon of youth. His novel depicts the youth with westernization and modernization in their life style and manners. His characters are social rebels and stands for their vitality. His Three Mistakes of My Life: A Story about Business, Cricket and Religion gives as idea of the major narrative strands. The three protagonists of the novel are raising entrepreneurs and the plot revolves around their ups and downs of their business fortune. On the other hand the adaptation of this novel Kai Po Che means 'kite is cut', is based on the novel "The 3 Mistakes of My Life". It can be described as a wholesome cinematic experience. The story has been set in Ahmedabad during the years of 2000 - 02, the script of the film follows the lives o three friends - Ishaan, Govind and Omi and their desire to own a successful business and move out of a middle class root. The story revolves around their trials and travails as they set up a sports goods business and a cricket coaching academy, and their encounter with the Muslim world through ali, Ishaan's talented cricket disciple. The movie gradually builds to a climax set during the Gujarat genocide of Muslims during February - March 2002.
\end{abstract}

Keywords - Westernization, mordernization,, narrative, adaptation, cricket, genocide, etc.

Chetan Bhagat is one of the most mainstream and eminent living creators of India. He is one of the most loved authors of youthful India and has many time been delegated as a symbol of youth. His tale delineates the young with westernization and modernization in their way of life and habits. His characters are social dissidents and represents their essentialness. People are no more observed through the old idea which arrange men are predominant and ladies as sub-par. As by result of globalization and modernization people are given their due spot and regard, in their own keenness and capacities, they are believed to be working or considering side by side. As per him all his lady characters are solid and feministic. He needs his characters become good examples for little youngsters. They ought to be ladies of substance and not simply prop that occupy the space. His The 3 Mistakes of My Life: A Story about Business, Cricket and Religion gives as thought of the significant account strands. The three heroes of the novel are raising business people and the plot spins around their high points and low points of their business fortune. The epic starts with the creator getting a self destruction mail from an individual named Govind in Ahmedabad. Bhagat gets astonished and discovers the kid. He additionally comes to meet him to know the purposes for his self destruction. The remainder of the story is described by Govind. Govind, Ishaan and Omi are beloved companions. Govind originates from a helpless family with just a mother who attempts to make their living by running a little hand crafted food shop. He adds to the accounts by offering educational costs to understudies in Math. Ishaan isn't acceptable in examines. His solitary energy is cricket. His dad is furious with him since he left National Defense Academy and got back. Omi has a place with a steadfast Hindu Brahmin family; his dad is the minister of a sanctuary. Omi is required to convey this custom of turning into a cleric from which he needs to get away. One day Govind chooses to introduce a shop selling cricket stuff. Omi's folks permit them to lease a little spot inside the sanctuary premises. While Govind deals with the record, Omi and Ishaan run the shop. As Govind scored hundred imprints in Maths in his sexually transmitted disease 
$\mathrm{X}$, Ishaan demands Govind to instruct Maths to his more youthful sister Vidya for her forthcoming clinical selection tests. Govind concurs reluctantly. Vidya is a juvenile little youngster who has no enthusiasm for Math or medication. She needs tohave the opportunity to make every second count. The shop works out in a good way for certain vacillations. Anyway Govind needs to grow his business. He sets aside cash and pays an underlying portion for another shop in Navrangpura Mall which will be opening in no time The primary slip-up of Gonvid Patel. Taneesha Kuishrestha comments:

"What strikes you first about Chetan Bhagat's novels is the fact that this author writes about Indians and for Indians. His characters are young, ambitious and passionate and have the same moral, social and religious dilemmas as many of the young Indians today. At the same time their context and sensibility too is unabashedly Indian. The new and the third Bhagat book, "The 3 mistakes of my life", has all these qualities." I

On 26th January toward the beginning of the day, individuals all over world were frightened to get the updates on an overwhelming quake which demolished numerous structures in Gujarat. Govind is devastated to see the state of his fantasy shop in Navaranpura Mall, yet with the help from companions and his mom he returns to taking care of his little shop. Omi's maternal uncle Bitto mother an individual from a Hindu Political Party and enthusiast of Parekh Ji, the pioneer of this gathering regularly visits their shop. $\mathrm{He}$ frequently hauls these children to his political gatherings. Then Ishaan catches wind of a skilled kid named Ali who hits a six at each ball. Ishaan looks at him yet Ali gets exhausted after each fourth ball and has a cerebral pain. He takes him to Dr.Multani who discloses to them that Ali is honored with outstandingly quick reflexes and this squeezes his mind. Ishaan chooses to mentor him, develop his endurance and set him up to be a public cooperative person. $\mathrm{He}$ gives Omi the duty of his eating routine as he is malnourished. Omi first rejects Ishaan's proposition since he is a Muslim and child of Bitoo mother's main adversary a pioneer of mainstream party. He later consents to support Ali yet stays quiet about everything. After significant preparing there is improvement in Ali's endurance. Ishaan wishes to take him to an India-Australia coordinate and acquaint him with some compelling individual who could assist Ali with turning into an effective cricketer. The three, alongside Ali figure out how to arrive at the VIP hall in Goa. There they meet an Australian cricketer Fred Li who sees Ali's ability and vows to support them and masterminds frothier passes to Australia. Ali gets a grant for cricket preparing in Australia however on condition that he would play for Australia yet Ali denies saying that he might want to play just for India. At some point, while in Australia, Govind acknowledges he is missing Vidya. He considers her and communicates his emotions. Omi comes to think about their relationship yet cautions Govind about the conventions of the general public. Love blooms between the two. The trio, along, with Ali comes back to Ahmedabad and return to their work. Love arrives at its extraordinary among Govind and Vidya and on her birthday they submit the offense of having sexual connection the second error of Govind. He is embarrassed about having a sexual illicit relationship with his closest companion's sister. Sweta Paspulati argues that:

"It does make you think about certain aspects and the feeling lingers with you for a long time. That is what you would remember after many long years that you have read the book and of course guys would remember the Cricket and the girl."

In the midst of every one of these occurrences breaks out a common uproar when a train bogie conveying a company of Hindu supporters, alongside Bitoo mom's child Dheeraj was as far as anyone knows burnby Muslims. Hindu fomenters drove by Bitoo mom consumed and slaughtered a few Muslims in the neighboring towns. Ali descends for every day practice to Ishaan. Ishaan took the kid to a sheltered spot; an old structure where these companions would accumulate now and again. Omi and Govind went along with them as well. The horde arrives at the structure requesting Ali is given over to them with the goal that they could complete him as they had slaughtered his folks. The three attempted their level best to control the horde. They consumed a couple by blowing a chamber, however the crowd was in furor. Omi gets unintentionally executed by his mom when he attempts to spare Ali. At last, Bitoo mother had Ali in his hold. Govind misses saving Ali by a brief instant and Ali's wrist gets cut-the third misstep of Govind. Bitoo mom gets slaughtered in the battle. Ishaan is angry with Govind for intuition childishly and for his postponement in ensuring Ali. He likewise finds Govind's relationship with his sister and is frantic at him. Govind reprimands himself for all the tragic occasions and attempts to end it all however he is spared. His mom persuades Ishaan to excuse him. Ishaan, with his sister, comes to meet Govind 
in the clinic and they become companions once more. Govind vows to pay for Ali's treatment. Ali completes medical procedure which turns fruitful and he by and by begins rehearsing cricket. The book closes with Govind consenting to enable the writer to compose a book on his three errors.

This tale depends on the genuine episodes and adjusts with genuine occurrences like Gujarat quake, 9/11 assault, Godhra damage and uproars too accept cricket matches. The book gives close to genuine depiction of why numerous understudies scorn Math, a sort of insider perspective on political decision legislative issues and Gujarat revolts, the difficulties and contrasts individuals face while pursuing huge dreams and then some. The book mirrors the run of the mill life in Ahmedabad old city, where individuals have their own needs and mirrors the ordinary business outlook of Gujarati people group and the effect of common uproars.

In this novel, the setting is the city of old Ahmedabad which however urban, is yet not as cosmopolitan city the same number of India's other metropolitan urban communities. It has the characteristics of modest community and old world in pols or settlements with conventional Indian family unit foundation. The characters are youthful, aspiring and energetic and have a similar good, social and strict problems the same number of the youthful Indians today. Simultaneously, their unique circumstance and reasonableness also is audaciously Indian. Chetan Bhagat has explained minutely the attitude and the expectation for everyday comforts of the individuals living in the pols. The development of the region (inhabitants in it) is with the end goal that they have to turn on tube-light in any event, during daytime hitch shows the crowed pols and thin boulevards in the old city where individuals need to live. Bhagat has reliably depicted the humble community mindset in India. They are principally inspired by others lives. The main activity of ladies living in pols is the tattle. In the novel, individuals concoct the tattles like the hypothesis about Omi turning out to be inept on the grounds that a cricket ball hit him or that Ishaan was tossed out of NDA and didn't flee or that Govind became unfeeling the day his father left the home. Everybody in the pol discusses these things however they are pointless and good for nothing. Sandhya Iyer in her review says :

"The last few chapters especially go out of hand. One knows Chetan's a big fan of Bollywood and believes that much like a Hindi film that must have action in the end, a novel too must have its share of blood and gore to make it wholesome enough. First of all, Bollywood itself is moving away from formulaic fares so Chetan's jumped in a bit late here. Secondly, there is no emotional resonance or reasoning to any of the violence that takes place in the temple, with the Hindus trying to attack Ali with Ishan and others trying to save him."

All the primary characters having own enthusiasm and fixation in the novel reflects specific class of youth and their concern. The tale mirrors the state of little scope business and their issues, the Indian legislative issues, common partitions, collective mobs, cricket rage in India alongside mentality of the present youth to these issues. Govind recounts to his story as a piece of telling his three errors that lead him to self destruction.

Abhishek Kapoor's executive film "Kai Po Che", signifies 'kite is cut', depends on the novel "The 3 Mistakes of My Life". It tends to be depicted as a healthy artistic encounter. The story has been set in Ahmedabad during the long periods of $2000-02$, the content of the film follows the lives o three companions - Ishaan, Govind and Omi and their craving to claim a fruitful business and move out of a white collar class root. The story rotates around their preliminaries and struggles as they set up a games products business and a cricket instructing foundation, and their experience with the Muslim world through ali, Ishaan's skilled cricket pupil. The film slowly works to a peak set during the Gujarat massacre of Muslims during February - March 2002.

Kai Po Che is an exceptionally smooth film, flawlessly shot and altered. It has some magnificent exhibitions by the principle entertainers, and some extremely contacting minutes. A portion of different minutes that there are no unimportant logical discourses on Hindu - Muslim Bhai - chaara, the film sends avery solid message for non savagery, it creates some extremely charming and reasonable characters like Omi's dad - a Hindu non - collective sanctuary cleric, Vidya, Ishaan's sister - a fiery Gujarati young lady who doesn't stop for a second to make a first move with a man she prefers, and afterward obviously Ali the peaceful youngster having a decent bating expertise in the sport of cricket. Sudhish Kamat says:

"Kai Po Che reminds us of another mostly fantastic approximation of India- Mani Ratnam's Bombay, a melting pot of culture and boiling communal tensions. A film that resorted to a Utopian ending after neatly facing off one 
community against another, through strategic character types in microcosm of India". 4

Notwithstanding all that is going for the film, I have seen that Kai Po Che is a dangerous film past its story structure and even illustrative personality of governmental issues. Truth be told somehow or another the film does fairly well in its introduction of the Muslim people group. The Muslims are obviously partnered with the mainstream Gandhian ideological group, Muslims are not indicated using weapons of any sort in the film - in actuality the overall powerlessness of Ali's dad when their home is assaulted by a traditional of Hindu horde is extremely moving. The Hindu are appeared to make the primary move - regardless of whether it is the pulling down of Ali's pajama in the play area by a lot of menaces, or the overall lack of care and refusal of help to Muslims after the seismic tremor. It was an alleviation to not perceive any visuals of meat shops, people continually performing namaz, or heaps of burqa wearing ladies. Truth be told one could even overlook the ever present skull tops. Kai Po Che produces a white washed rendition of the narrative of the Gujarat destruction of 2002. The issue with this film is that it makes the Gujarat massacre of 2002 acceptable to the crowd. The destruction devoured in a brief peak, wher at long last the compassion isn't even with the people in question. Truth be told new 'casualties' are made - Ishaan, who forfeits his life for Ali, Omi, who has just lost his folks, presently coincidentally winds up slaughtering his closest companion and goes through ten years in prison and Govind, who loses his companion and Vidya, who loses her sibling.

A main point of interest with the movie is that the brutality executed on the Muslims is straightforwardly connected to the train misfortune at Godhra station in which around 60 individuals passed on. The unpredictability of those connections and the ensuing enquiries into the Sabarmati Express fire are not something that the movie producer even alludes to. We as a whole concur that the train fire at Godhra station was an extremely lamentable scene, yet we likewise realize the issue is significantly more convoluted. I am certain that the filmmaking group had done through examination into this, yet they picked the state line. They pick practicality over genuineness.

In Kai Po Che, the brutality against the Muslims is pitched as an unconstrained erupt in light of the fact that supposedly the Muslims of Godhra burnt the Sabarmati express in which numerous guiltless individuals kicked the bucket, including Omi's folks. The film portrays Omi's fierceness against the muslims, his total conviction that it was the Muslims who murdered who executed his folks, and henceforth the defense for assaulting the Muslims in ahmedabad. The Film denounces Omi's savagery. Surely it asks Omi to be a superior individual. Yet, the simple reason - impact connection among Godhra and the Gujrat program and the oversimplified connection among activity and response that the film sustains is inadmissible to me. No correct reasoning individual - the producers, pundits crowd will say that brutality is something worth being thankful for, however canister the film, the characters are apparently lenient of flare-ups, unconstrained upheavals of youth, and slip-ups that assume the state of mass killings, assaults, plunder and obliteration of property. Vinayak Chakravorty comments that:

"Kai Po Che uses its runtime well, regaling with a simple story of dreams even as it touches the complexity of modern India's most shameful socio-political chapter. The film is among Bollywood's best so far this year." 5

The film effectively coordinates compassion with the three companions - All feeling is ascribed to Ishaan, Govind and Omi. After the peak we overlook the mercilessness of this pre-arranged brutality; we even overlook that it was pre-arranged. The brutality on the Muslims isn't despicable any longer, yet Ishaan's demise is. The film has a reasonable message that it has been ten years of that occurrence, presently it's an ideal opportunity to excuse, overlook and proceed onward.

\section{REFERENCES}

[1] https://www.livemint.com/Consumer/jMIN1mn63tv6qMnzzR 0ASJ/Book-review--The-3-mistakes-of-my-life.html

[2] https://wittysparks.com/book-review-the-3-mistakes-of-mylife-chetan-bhagat/

[3] http://sandyi.blogspot.com/2008/05/book-review-threemistakes-of-my-life.html

[4] https://www.thehindu.com/features/cinema/kai-po-che-reviewno-mistakes-our-life/article4446273.ece

[5] https://www.indiatoday.in/movies/reviews/story/kai-po-chemovie-review-154669-2013-02-22 